JAMP: Jurnal Adminitrasi dan Manajemen Pendidikan Volume 5 Nomor 1 Maret 2022, Hal : 71 - 76

Tersedia Online di http://journal2.um.ac.id/index.php/jamp/ ISSN 2615-8574 (online)

\title{
ANALISIS KARAKTERISTIK RESPONDEN DALAM MENGGALI PELAKSANAAN TUGAS PROFESI GURU MELAKSANAKAN PENDIDIKAN MASA PANDEMI DI SEKOLAH DASAR
}

\author{
Erika Mei Budiarti'; Desi Eri Kusumaningrum²; Wildan Zulkarnain ${ }^{3}$; \\ Raden Bambang Sumarsono ${ }^{4}$; Akbar Syach Ichwanda Burham ${ }^{5}$; Evanly Jorji Bengen ${ }^{6}$ \\ ${ }^{1}$ Jurusan Manajemen Pendidikan Islam Fakultas Agama Islam \\ Universitas Hasyim Asy'ari Tebuireng Jombang \\ Jalan Irian Jaya No. 55 Cukir Kecamatan Diwek Kabupaten Jombang Jawa Timur Indonesia \\ ,2,3,4,5 Jurusan Administrasi Pendidikan Fakultas Ilmu Pendidikan \\ Universitas Negeri Malang \\ Jl. Semarang No. 5 Malang Jawa Timur Indonesia \\ E-mail: meierika09@gmail.com
}

\begin{abstract}
The purpose of this study was to describe the characteristics of the selected respondents in implementing education during the pandemic in public elementary schools in the Greater Malang area (Malang City, Malang Regency, and Batu City). The data analysis technique used is descriptive analysis. The research sample selected was teachers in public elementary schools in the Greater Malang area (Malang City, Malang Regency, and Batu City). The conclusions of the study that resulted from the characteristics of gender, age, salary/income level, and employee status varied widely.
\end{abstract}

Keyword: characteristic, staff, profession

\begin{abstract}
Abstrak: Tujuan dari penelitian ini adalah untuk mengetahui gambaran karakteristik responden yang terpilih dalam melaksanakan pendidikan di masa pandemic di sekolah dasar negeri wilayah Malang Raya (Kota Malang, Kabupaten Malang, dan Kota Batu). Teknik analisis data yang digunakan adalah analisis deskriptif. Sampel penelitian yang dipilih adalah para guru di lingkungan sekolah dasar negeri wilayah Malang Raya (Kota Malang, Kabupaten Malang, dan Kota Batu). Kesimpulan penelitian yang dihasilkan dari karakteristik jenis kelamin, usia, tingkat gaji/ pendapatan, dan status pegawai sangat bervariasi.
\end{abstract}

Kata Kunci: karakteristik, pegawai, profesi

penyebaran Covid-19 di Indonesia sejak awal tahun 2020 merubah banyak aspek kehidupan bangsa. Salah satu aspek yang menjadi perhatian besar adalah proses pelaksanaan pendidikan. Pelaksanaan pendidikan di masa pandemi berubah dari pembelajaran tatap muka langsung menjadi pembelajaran tidak langsung (online learning). Pembelajaran tidak langsung tersebut menjadi salah satu upaya agar bangsa Indonesia tetap dapat mendapatkan hak layanan pendidikan tetapi dengan jalan agar penyebaran Covid-19 tidak semakin meluas karena adanya kerumunan di lembaga pendidikan.

Sistem pembelajaran daring (online learning) menurut Ruskan (2012) dan Basori (2017) ialah pembelajaran yang dilakukan melibatkan koneksi jaringan internet dalam menyampaikan amteri pelajaran, interaksi, ataupun bimbingan yang diberikan oleh guru kepada peserta didiknya. Artinya, proses pembelajaran secara daring ini dilakukan tanpa adanya pertemuan tatap muka secara langsung antara pendidik dan peserta didiknya. Pembelajarn online seperti ini tidak dipungkiri lagi akan banyak terjadi kendala dan hambatan dalam pelaksanaannya karena kondisi geografis dan demografis bangsa Indonesia yang begitu beragam. 
Pada kondisi seperti ini, sinergi antara sekolah, keluarga, dan masyarakat harus dibangun secara serius dan berkesinambungan agar tujuan pendidikan bisa tercapai dengan maksimal. Kendali pelaksanaan pendidikan secara jarak jauh (pebelajaran onling) dari sisi lingkungan sekolah ada pada tangan para pendidik di Indonesia, baik jenjang pendidikan dasar, menengah bawah, maupun menengah atas. Baik pendidikan formal maupun non-formal. Berdasarkan penelitian yang telah dilakukan Zulkarnain, Kusumaningrum, dkk (2021) didapatkan hasil bahwa pelaksanaan tugas profesi guru dalam melaksanakan pendidikan di masa pandemic berada pada kategori "sangat tinggi" dengan persentase sebesar $61,3 \%$.

Penelitian yang dilakukan ditelusuri lebih lanjut datanya oleh peneliti terkait dengan karakteristik respondennya. Hal menarik yang menjadi ketertarikan peneliti adalah hasil penelitian yang tinggi pada variabel tugas profesi guru dalam melaksanakan tugasnya di masa pandemi, padahal seperti diketahui hari ini banyak sekali terjadi hambatan/masalahmasalah di lapangan pada prosesnya. Hal-hal atau karakteristik apa saja yang turut mengikuti hasil penelitian tersebut. Seperti yang dijelaskan oleh Bahmid (2016) bahwasannya usia dan masa kerja memiliki determinasi sebesar $71.7 \%$ terhadap kinerja guru. Hal tersebut juga turut dijelaskan oleh Robbins (2003) bahwasannya hubungan antara usia (umur) dengan kinerja menjadi isu penting yang akan semakin berkembang selama dekade yang akan datang.

Permanasari (2001) juga menjelaskan melalui simpulan penelitiannya bahwa perbedaan prestasi kerja karyawan (pegawai) ditinjau dari usia, tingkat pendidikan, dan masa kerja yang menunjukkan bahwa ada perbedaan prestasi kerja karena faktor usia. Demikian pula dengan Supriyono (2006) menjelaskan bahwa pengaruh usia, keinginan sosial, kecukupan anggaran, dan partisipasi anggaran terhadap kinerja manajer menunjukkan bahwa usia mempunyai pengaruh positif dan signifikan terhadap kinerja.

Berdasarkan analisis di atas, peneliti tertarik untuk melakukan penelitian untuk selanjutnya dianalisis terkait beberapa karakteristik yang menjadi bagian menyatu dalam diri responden. Dalam rangka menggali data terkait pelaksanaan tugas profesi guru di masa pandemic pada jenjang sekolah dasar negeri wilayah Malang Raya.

\section{METODE}

Penelitian ini dilakukan di sekolah dasar negeri se-Malang Raya (Kota Malang, Kabupaten Malang, dan Kota Batu) pada bulan Agustus hingga September 2021. Jenis penelitian ini menggunakan desain penelitian kuantitatif analisis deskriptif. Sampel penelitian berjumlah 93 responden dengan menggunakan rumus Slovin dan menggunakan teknik pengambilan sampel simple random sampling. Data yang digunakan didapatkan dari hasil mengisi kuesioner yang telah dibuat oleh peneliti kemudian diberikan kepada responden.

\section{HASIL DAN PEMBAHASAN}

Karakteristik responden yang digambarkan dalam penelitian ini berdasarkan jenis kelamin, usia, gaji, dan status pegawai. Hasil analisis atas beberapa karakteristik yang dipilih peneliti menunjukkan hasil sebagai berikut.

\section{Karakteristik Responden Berdasarkan Jenis Kelamin}

Tabel 1 di bawah ini menunjukkan bahwa sebagian besar $(74,2 \%)$ responden adalah perempuan, sementara sebanyak $25,8 \%$ adalah responden laki-laki. 
Tabel 1 Tabel Hasil Analisis Karakteristik Jenis Kelamin

\begin{tabular}{llllll}
\hline & & Frequency & Percent & Valid Percent & $\begin{array}{l}\text { Cumulative } \\
\text { Percent }\end{array}$ \\
\hline Valid & Laki - Laki & 24 & 25.8 & 25.8 & 25.8 \\
& Perempuan & 69 & 74.2 & 74.2 & 100.0 \\
& Total & 93 & 100.0 & 100.0 & \\
\hline
\end{tabular}

\section{Karakteristik Responden Berdasarkan Usia}

Apabila dilihat dari karakteristik kelompok usia, persentase terbesar pada usia produktif yaitu pada usia 31-40 tahun sebesar 37,6\%; disusul oleh rentang usia 41-50 tahun sebesar 30,1\%; kemudian rentang usia 21-30 tahun sebesar 24,7\%; selanjutnya rentang usia 51-60 tahun sebesar 6,5\%; dan paling akhir sebesar 1,1\% pada rentang usia di atas 61 tahun. Dilihat dari proporsi responden berdasarkan usia tampak bahwa dalam menjalankan tugas profesi guru usia produktif rentang 31-40 tahun adalah sasaran utama.

Tabel 2 Tabel Hasil Analisis Karakteristik Usia

\begin{tabular}{llllll}
\hline & & Frequency & Percent & Valid Percent & $\begin{array}{l}\text { Cumulative } \\
\text { Percent }\end{array}$ \\
\hline Valid & $21-30$ & 23 & 24.7 & 24.7 & 24.7 \\
& $31-40$ & 35 & 37.6 & 37.6 & 62.4 \\
& $41-50$ & 28 & 30.1 & 30.1 & 92.5 \\
& $51-60$ & 6 & 6.5 & 6.5 & 98.9 \\
& lebih dari 61 & 1 & 1.1 & 1.1 & 100.0 \\
& tahun & & & & \\
& Total & 93 & 100.0 & 100.0 & \\
\hline
\end{tabular}

\section{Karakteristik Responden Berdasarkan Gaji}

Pada Tabel 3 tampak bahwa rentang gaji/pendapatan yang paling rendah yaitu Rp 100.000,00 Rp 1.000.000,00 memilik persentase hasil terbesar yaitu sebesar 38,7\%; dilanjutkan oleh kelompok gaji rentang Rp 3.100.000,00 - Rp. 4.000.000,00 sebesar 25,8\%; disusul oleh kelompok gaji rentang Rp 2.100.000,00 - Rp. 3.000.000,00 sebesar 20,4\%; dan dilanjutkan oleh kelompok gaji rentang Rp 1.100.000,00 - Rp. 2.000.000,00 sebesar 7,5\%; kemudian rentang gaji Rp 4.100.000,00 - Rp $5.000 .000,00$ sebesar 6,5\%; dan yang paling akhir dengan nominal kelompok gaji terbesar lebih dari $\mathrm{Rp}$ $5.100 .000,00$ memiliki frekuensi paling kecil yakni sebesar $1,1 \%$.

Dari data tersebut dapat dijadikan pertimbangan dalam pengambilan kebijakan terkait apresiasi pelaksanaan tugas profesi guru berada pada rentang gaji yang paling rendag yakni Rp $100.000-\mathrm{Rp}$ 1.000.000,00 sementara rentang gaji yang paling besar di atas Rp 5.100.000,00 justru memiliki frekuensi yang paling kecil.

Tabel 3 Tabel Hasil Analisis Karakteristik Gaji

\begin{tabular}{llllll}
\hline & & Frequency & Percent & Valid Percent & $\begin{array}{l}\text { Cumulative } \\
\text { Percent }\end{array}$ \\
\hline Valid & $100.000-1.000 .000$ & 36 & 38.7 & 38.7 & 38.7 \\
& $1.100 .000-2.000 .000$ & 7 & 7.5 & 7.5 & 46.2 \\
& $2.100 .000-3.000 .000$ & 19 & 20.4 & 20.4 & 66.7 \\
$3.100 .000-4.000 .000$ & 24 & 25.8 & 25.8 & 92.5 \\
4.100.000-5.000.000 & 6 & 6.5 & 6.5 & 98.9 \\
lebih dari 5.100.000 & 1 & 1.1 & 1.1 & 100.0 \\
Total & 93 & 100.0 & 100.0 & \\
\hline
\end{tabular}




\section{Karakteristik Responden Berdasarkan Status Pegawai}

Hasil penelitian menunjukkan bahwa sebagian besar dengan persentase frekuensi sebesar 55,9\% responden bekerja sebagai tenaga pendidik (guru) dengan status pegawai Non-PNS dan sisanya sebesar $44,1 \%$ adalah tenaga pendidik (guru) berstatus PNS. Sehingga dapat dilihat bahwa tugas profesi guru di wilayah Malang Raya memiliki kategori sangat tinggi pelaksanaanya di saat pandemic adalah dari kelompok guru berstatus Non-PNS.

Tabel 4 Tabel Hasil Analisis Karakteristik Status Pegawai

\begin{tabular}{llllll}
\hline & & Frequency & Percent & Valid Percent & $\begin{array}{l}\text { Cumulative } \\
\text { Percent }\end{array}$ \\
\hline Valid & PNS & 41 & 44.1 & 44.1 & 44.1 \\
& Non-PNS & 52 & 55.9 & 55.9 & 100.0 \\
& Total & 93 & 100.0 & 100.0 & \\
\hline
\end{tabular}

\section{Distribusi Responden Berdasarkan Jenis Kelamin}

Pada Gambar 1 di bawah ini tampak bahwa responden berjenis kelamin perempuan sebesar $74 \%$ memberikan kontribusi setenga lebih dari data penelitian yang didapatkan dalam mengukur pelaksanaan tugas profesi guru melaksanakan pendidikan di masa pandemic jenjang sekolah dasar negeri se-Malang Raya.

Jenis kelamin yang dimaksud adalah guru laki-laki dan guru peremouan. Secara psikologis lakilaki dan perempuan memiliki perkembangan yang berbeda. Waluyo (2015) menjelaskan bahwa guru laki-laki dalam menghadapi siswanya lebih banyak mengajar berdasarkan pengalamannya saat masih belajar, sedangkan guru peremuan lebih banyak menggunakan sistem pengajaran yang sesuai dengan ketetapan pendidikan yang berlaku juga ditambah adanya perasaan peka dari kondisi seorang pelajar yang dapat dirasakan oleh kaum guru perempuan.

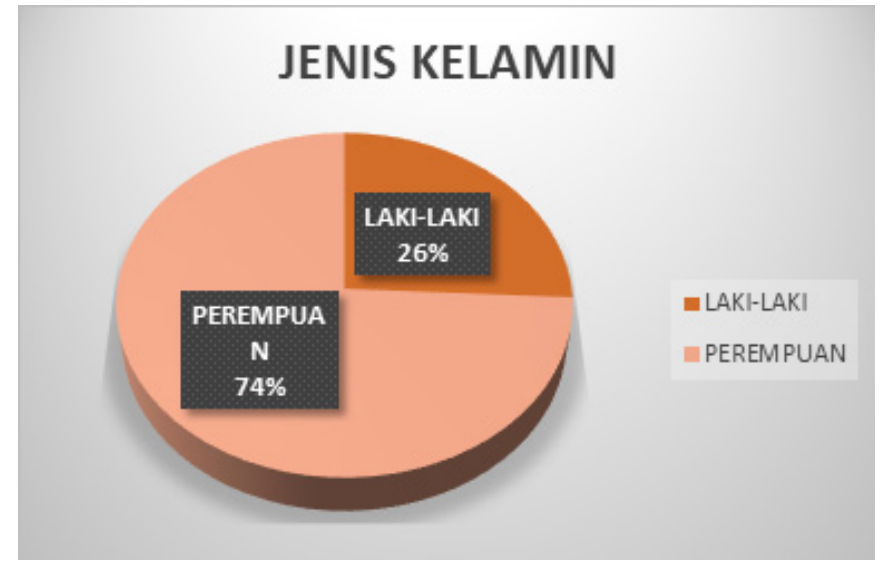

Gambar 1 Distribusi Responden Berdasarkan Jenis Kelamin

\section{Distribusi Responden Berdasarkan Usia}

Pada Gambar 2 di bawah ini tampak bahwa responden berusia produktif $31-40$ tahun memiliki persentase terbesar yaitu sebesar 38\%; disusul oleh rentang usia 41-50 tahun sebesar 30,1\%; kemudian rentang usia 21-30 tahun sebesar 24,7\%; selanjutnya rentang usia 51-60 tahun sebesar 6,5\%; dan paling akhir sebesar $1,1 \%$ pada rentang usia di atas 61 tahun.

Adanya rentang perbedaan usia dan rentang perolehan persentase tersebut menandakan bahwa perbedaan usia pada guru biasanya membuat kualitas mengajar guru juga turut berbeda. Gellerman (dalam Waluyo: 2015) menjelaskan bahwa pada umumnya para pekerja muda memiliki tingkat harapan dan ambisi yang tinggi. Begitu juga dengan para pekerja guru pada usia 31-40 tahun dianggap usia produktif, memiliki semangat dan ambisi tinggi serta sudah memiliki kecukupan pengalaman sehingga pelaksanaan tugas profesinya juga sebanding dengan semangat dan pengalaman yang dimiliki. 


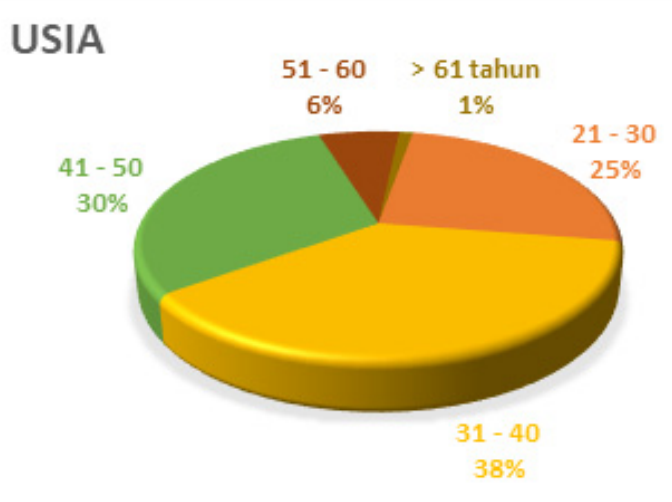

Gambar 2 Distribusi Responden Berdasarkan Usia

\section{Distribusi Responden Berdasarkan Gaji}

Pada Gambar 3 tampak bahwa rentang gaji/pendapatan yang paling rendah yaitu Rp 100.000,00 - Rp 1.000.000,00 memilik persentase hasil terbesar yaitu sebesar 38,7\%; dilanjutkan oleh kelompok gaji rentang Rp 3.100.000,00 - Rp. 4.000.000,00 sebesar 25,8\%; disusul oleh kelompok gaji rentang Rp 2.100.000,00 - Rp. 3.000.000,00 sebesar 20,4\%; dan dilanjutkan oleh kelompok gaji rentang Rp 1.100.000,00 - Rp. 2.000.000,00 sebesar 7,5\%; kemudian rentang gaji Rp 4.100.000,00 - Rp $5.000 .000,00$ sebesar 6,5\%; dan yang paling akhir dengan nominal kelompok gaji terbesar lebih dari Rp 5.100.000,00 memiliki frekuensi paling kecil yakni sebesar 1,1\%.

Hasil penelitian di atas bertolak belakang dengan hasil penelitian dari Restiana (2012) bahwa gaji memiliki penagruh positif dan signifikan terhadap variabel lingkungan kerja dan kinerja guru tetap. Diperkuat pula oleh Fadhillah (2010) yang mana hasil penelitiannya juga bertolak belakang dari hasil penelitian yang dilakukan oleh peneliti, dimana Fadhillah menjelaskan bahwa terdapat pengaruh antara tingkat pendapatan guru dengan kinerja guru dalam mengajar.

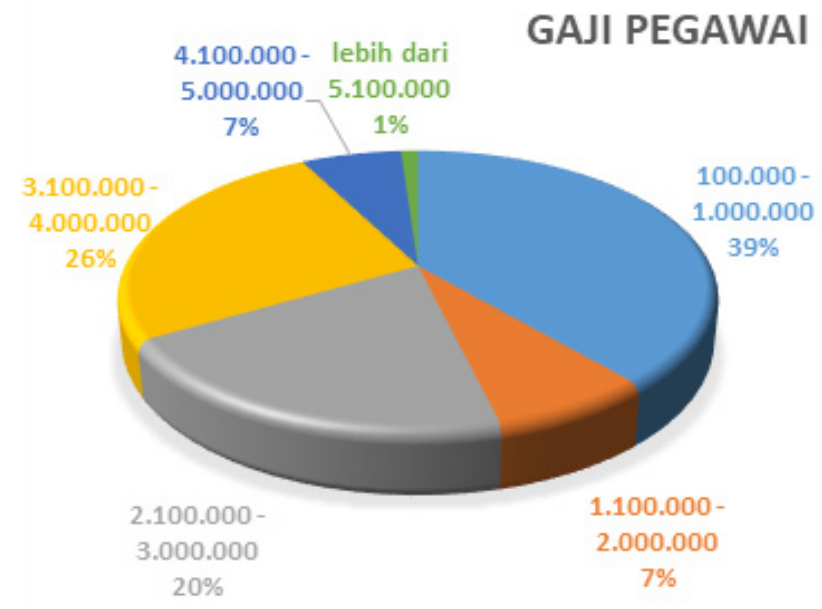

Gambar 3 Distribusi Responden Berdasarkan Gaji

\section{Distribusi Responden Berdasarkan Status Pegawai}

Pada Gambar 4 di bawah ini tampak bahwa responden sebagian besar berstatus sebagai pegawai Non-PNS sebesar 56\% dan pegawai berstatus PNS sebesar 44\%. Hasil penelitian tersebut bertolak belakang dengan hasil penelitian terdahulu yang telah dilakukan oleh Wahyuningsih dan Wibowo (2011) dimana perbedaan motivasi kerja guru PNS lebih tinggi dibandingkan dengan motivasi kerja guru Non-PNS. 


\section{STATUS PEGAWAI}

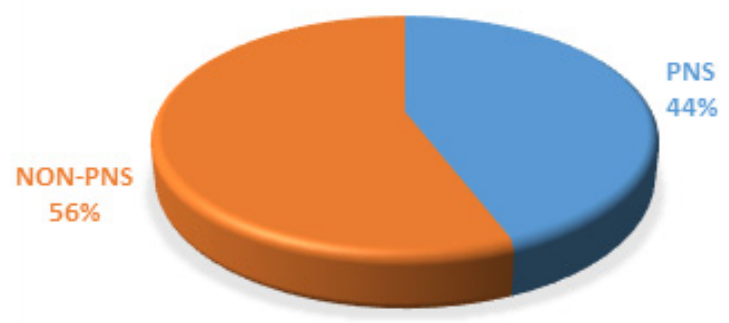

Gambar 4 Distribusi Responden Berdasarkan Status Pegawai

\section{KESIMPULAN}

Berdasarkan tujuan penelitian yang diajukan pada bab sebelumnya didapatkan hasil bahwa: responden berjenis kelamin perempuan sebesar 74\% memberikan kontribusi setenga lebih dari data penelitian yang didapatkan dalam mengukur pelaksanaan tugas profesi guru melaksanakan pendidikan di masa pandemic jenjang sekolah dasar negeri se-Malang Raya. Dengan para pekerja guru pada usia 31-40 tahun dianggap usia produktif, memiliki semangat dan ambisi tinggi serta sudah memiliki kecukupan pengalaman sehingga pelaksanaan tugas profesinya juga sebanding dengan semangat dan pengalaman yang dimiliki. Tingkat pendapatan (gaji) tidak berpengaruh terhadap kinerja guru karena pada penelitian ini gambaran gaji rentang terkecil memiliki tingkat tugas profesi guru yang tinggi. Status pegawai Non-PNS berkontribusi lebih besar dalam melaksanakan tugas profesi guru dibandingkan pegawai berstatus PNS.

\section{DAFTAR RUJUKAN}

Bahmid, K. 2016. Pengaruh Usia dan Masa Kerja terhadap Kinerja Guru di MAN Sidikalang Tahun Ajaran 2015/2016. Medan: Digital Repository Universitas Negeri Medan.

Fadhillah, C. 2010. Tingkat Pendapatan Guru dan Pengaruhnya terhadap Etos Kerja Guru dalam Mengajar: Studi Kasus di SMP Islam Cirendeu. Ciputat: FITK UIN Jakarta.

Permanasari, M.A. 2001. Analisis Perbedaan Prestasi Kerja Karyawan Ditinjau dari Usia, Tingkat Pendidikan, dan Masa Kerja. Yogyakarta: USD.

Restiana, N. 2012. Pengaruh Kompensasi, Lingkungan Kerja, dan Motivasi Kerja terhadap Kinerja Guru Tidak tetap SD/MI Kabupaten Kudus. Semarang: Universitas Diponegoro.

Robbins, S.P. 2003. Organizational Behavior $11^{\text {th }}$ ed. New Jersey: Prentice-Hall.

Supriyono, R.A. 2006. Jurnal Ekonomi dan Bisnis Indonesia. Volume 21 Nomor 1. Yogyakarta.

Wahyuningsih, S. \& Wibowo, E. 2011. Perbedaan Motivasi kerja Guru PNS dan Non-PNS dilihat dari Kepemimpinan, Kepuasan Gaji, dan Lingkungan Kerja. Jurnal Manajemen Sumberdaya Manusia. Volume 5 Nomor 2 Desember 2011.

Waluyo, M. 2015. Manajemen Psikologi Industri. Jakarta: PT. Indek 